\title{
1 Evaluations of accents can be used as a measure of prestige
}

2

3 Alarna N. Samarasinghe ${ }^{1^{*}}$, Richard E. W. Berl' ${ }^{2}$, Michael C. Gavin ${ }^{2,3}$, Fiona M. Jordan ${ }^{1,3}$

4

$5 \quad{ }^{1}$ Department of Anthropology and Archaeology, University of Bristol, Bristol, UK

$6^{2}$ Department of Human Dimensions of Natural Resources, Colorado State University, Fort Collins, CO, USA

$7 \quad{ }^{3}$ Department of Linguistic and Cultural Evolution, Max Planck Institute for the Science of

8

Human History, Jena, Germany

9

10*Author for correspondence: Alarna N. Samarasinghe (as15936@bristol.ac.uk)

11

$12 \underline{\text { Abstract }}$

13Sociolinguistic studies have established that people make judgements about 14speakers based on accent. Standard and non-standard accents have differing 15levels of prestige and demonstrate variation across other attitudinal terms. 16Because prestige can increase the likelihood of information transmission, we 17explore variation in accent prestige to determine whether accent can be used as 18a measure of prestige in social transmission experiments. Participants ( $n=152$ 19US; 142 UK) were presented with standardised recordings of a standard passage, 20containing lexical terms that highlight phonological differences between accents 21of English. Passages were spoken by middle-aged white male speakers 22representing a range of eight accents from the listener's country of residence and 23two from the alternative country. Participants rated the speakers on 24 different 24personal qualities including traits associated with prestige and friendliness. As 25 predicted, participants rated the standard accents favourably for prestige across 26both locations. Participants perceived location-specific non-standard accents as 27having lower prestige, and accents deemed as having lower prestige as being 28friendlier. Accent indexes differential qualities for listeners, regardless of 29 whether the concept is operationalised by the term "prestigious" or multiple 30terms related to 'prestige'. We assert that accent can be used as an indicator of 31 prestige in the absence of other prestige information and demonstrate the 32importance of locally calibrating the accents used in prestige-based social 33transmission experiments.

35Keywords: cultural evolution; sociolinguistics; prestige; language attitudes; accent; social 36 transmission biases 


\section{1. Introduction}

38Prestige bias has been well-studied in the cultural evolution literature in 39 evaluating the reasons why particular cultural traits are adopted over others. $40 H e r e$, we demonstrate how accent is a potential source of information bias in 41social learning, and this work is motivated by the need for a widely shared 42experimental mechanism of establishing prestige information. Although prestige 43can be indexed in many ways; experiments have tended to focus on attentional 44cues or deference as measures of prestige (Atkisson, Mesoudi, \& O’Brien, 2012; 45Brand \& Mesoudi, 2019; Chudek, Heller, Birch, \& Henrich, 2012; Henrich \& Gil46White, 2001; Jiménez $\&$ Mesoudi, 2019b). This is problematic because greater 47attention and deference are not just cues of prestige but a direct outcome. 48Accent, in contrast, is a relatively stable and accessible proxy for prestige across 49a broad range of speakers.

50 Accent is the variation in how speakers of a common language pronounce 51 words and, beyond the specific language variety itself, can index a variety of 52 social factors (e.g. age, gender, ethnicity, social class). Accents are typified by the 53proportion of specific linguistic variants expressed (e.g. the relative usage of 54phonemes [a:] and [æ] in 'bath' or 'trap'), and have been shown to be sufficiently 55 varied to stimulate differences in social preferences for even preverbal infants 56(Kinzler, Dupoux, \& Spelke, 2007).

57 As some accents are regionally bound (Alford \& Strother, 1990; Clopper \& 58Pisoni, 2006; Labov, Ash, \& Boberg, 2005; Shackleton, 2007; Wells, 1982), accent 59 can be used as a reliable marker of group identity. This is likely because accent is 60an honest signal; whilst some people can mimic other accents, it is difficult to 61maintain, especially when vernacular speech is elicited (Cohen, 2012). Accent $62 \mathrm{can}$, therefore, be used to reliably infer social information about the speaker and 63can be used in transmission studies to make judgments about which individuals 64(models) to copy.

65 Many studies have demonstrated that accent can be used to determine 66different types of social information about individuals and also with whom we 67associate and trust (Harris \& Corriveau, 2011; Kinzler, Corriveau, \& Harris, 2011; 68Kinzler \& DeJesus, 2013; Lev-Ari \& Keysar, 2010). As one example, English69 speaking children in the USA prioritise accent cues over visual cues of race when 70identifying others as in-group or not (Kinzler, Shutts, DeJesus, \& Spelke, 2009). 
71 Sociolinguists have demonstrated that people evaluate speakers by their 72accents for attitudinal qualities including prestige (Alford \& Strother, 1990; 73Bayard, Weatherall, Gallois, \& Pittam, 2001; Bishop, Coupland, \& Garrett, 2005; 74Boucher, Hammock, McLaughlin, \& Henry, 2013; Brown, Giles, \& Thakerar, 1985; 75Callan \& Gallois, 1987; Coupland \& Bishop, 2007; Fuertes, Gottdiener, Martin, 76Gilbert, \& Giles, 2012; Giles, 1970). In the sociolinguistic literature, accent-based 77 prestige is often considered a population-level attribute and related to whether 78an accent is deemed a standard form or not, rather than being determined by an 79individual's success or expertise. Standard accents (e.g. "Received 80Pronunciation”, “General American”) are often considered to carry prestige and 81are not locality-specific (Morales, Scott, $\&$ Yorkston, 2012). These accents 82 develop through a process of standardisation, usually at the establishment level, 83and are therefore deemed an ideological aspiration (Coupland, 2003; Coupland 8 84Bishop, 2007). As such, the sociolinguistic literature distinguishes two types of 85prestige: (i) 'overt prestige', where listeners consciously ascribe positive status 86to a linguistic variable (i.e. accent difference) due to determinable attributes such 87as 'niceness'; and (ii) 'covert prestige', in which there is speaker movement 88toward linguistic variants that do not broadly have positive connotations 89(Meyerhoff, 2011). In this way, all accents (including non-standard, and foreign 90accents) can theoretically be afforded prestigious status (Hawkey, 2016). 91 Studies of accent perception have already been fruitfully applied in 92domains such as marketing (Laiwani, Lwin, \& Li, 2005; Lwin \& Wee, 1999; 93Morales et al., 2012; Tsalikis, Ortiz-Buonafina, \& LaTour, 1992; Z. Wang, Arndt, 94Singh, Biernat, \& Liu, 2013) and education (Eisenchlas \& Tsurutani, 2011; Gill, 951994; Rubin \& Smith, 1990; H. Wang \& Heuven, 2004). Although taken together 96these studies have considered a range of global accents of English, accent 97perception is usually tested with a single population. It is therefore unclear 98whether these perceptions are stable across populations. We argue that accent is 99a potentially useful cue of prestige that can be employed in experimental studies 100of human behaviour, including those on cultural transmission and evolution. 101Previous experiments investigating a prestige effect have provided information 102about the individual model, or attentional and deferential cues (Atkisson et al., 1032012; Brand \& Mesoudi, 2019; Chudek et al., 2012; Henrich \& Gil-White, 2001; 104Jiménez \& Mesoudi, 2019a), but many instances of everyday social information 
105transmission employ spoken language (e.g. teaching). If we can establish the 106utility of using accent as a cue for prestige, we can expand the variety of 107experimental designs we use, and ground social transmission studies in 108increasingly realistic behaviour. By using accent as a proxy for prestige, we can 109use speech on its own as an experimental manipulation, and therefore remove 110the complex, contextual, and poorly understood confounds of visual cues of 111prestige (e.g. posture and clothing (Daloz, 2009; Fişek, Berger, \& Norman, 1122005)). Furthermore, we can attenuate the self-perpetuating aspects of prestige 113in the visual modality such as attention and deference: by paying attention to 114 someone who others are paying attention to, we run the risk of contributing to 115their perceived prestige irrespective of whether initial attention is due to 116 prestige.

117 The aims of this paper are twofold: a) to replicate previous language 118attitude studies to determine whether attitudes towards different accents of 119English are both stable and widely shared, and therefore, can act as a reliable 120source of social information bias; and b) to specifically investigate how those 121 accents differ in prestige. Here, we present results from a language attitude 122survey where we presented a range of locally calibrated standard and 123nonstandard accents to participants. We expect that 1) accents are rated 124differentially on measures of prestige; 2) standard accents will have greater 125 prestige; and 3) non-standard accents will be perceived as less prestigious.

\section{2. Methods} 2.1 Ethical statement

130We obtained ethical approval from the University of Bristol Faculty of Arts 131Research Ethics Committee (protocols \#31041 and \#38323) and Colorado State 132University Institutional Review Board (protocol \#014-16H).

135We recruited participants for this task through online platforms Amazon 136Mechanical Turk and Turk Prime, and Prolific Academic for US ( $n=152)$ and UK $137(n=142)$ samples respectively. We compensated participants for their time at 
138rates above local minimum wages; rates were based on the time taken to 139complete the tasks.

142Participants from the US and the UK answered a short demographic 143 questionnaire and were presented with ten recordings of differently-accented 144speakers reading the Comma Gets a Cure passage (Honorof, McCullough, \& 145Somerville, 2000), a piece of text specifically written to discriminate between 146accents of English. Of the 10 recordings, eight were from the country in which 147the participant was based, and two were from the other country, providing a 148robustness check and a measure of how widespread accent perceptions are. 149Based on previous literature (Coupland \& Bishop, 2007; Giles, 1970; Labov et al., 1502005; Shackleton, 2007) we chose accents that represented both high and low 151prestige across both their own country and the other country. All speakers 152recited the same passage, so we presented participants with only the first 153paragraph of the passage (approximately 30 seconds) to shorten the overall 154length of the study and to ensure that participants' engagement with the task 155 was not compromised due to attention loss. We informed participants that they 156would hear the same passage in each recording and were not required to pay 157attention to content, allowing them to focus on the voices. As they listened to 158each recording, participants rated the speakers on a seven-point Likert-type 159scale for 24 attitudinal variables.

160

162All but two recordings were sourced from the International Dialects of English 163Archive (IDEA: https://www.dialectsarchive.com/). This archive stores over one 164thousand samples of speech in English comprising recordings and interviews. 165For many of these recordings, phonetic transcripts are provided, as well as a 166detailed history of where the speakers have lived. We used recordings of white, 167 male speakers between the ages of 31 and 59 years (mean age $=47.7$ years), as a 168previous unpublished pilot study found that younger, female voices were 169deemed less prestigious overall. We also included speakers who fit the 170demographic category with Colorado (American West) and Welsh accents who 171we recorded, diversifying our range of accents. 
173Table 1. Accents used from the UK and USA. Accents listed in bold were presented to both 174 populations.

\begin{tabular}{|c|c|c|}
\hline & UK Recordings & US Recordings \\
\hline \multirow{3}{*}{ 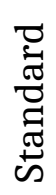 } & Received Pronunciation & Colorado (West, urban) \\
\hline & SE England & Wyoming (West, rural) \\
\hline & & Oklahoma (Midland) \\
\hline \multirow{4}{*}{ 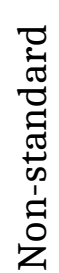 } & Ireland & Illinois (Inland North) \\
\hline & NW England & New York City \\
\hline & Scotland & North Carolina (Inland South, blue \\
\hline & SW England & collar) \\
\hline
\end{tabular}

175

176Recordings from IDEA are categorised by location: the USA recordings are 177indexed by state, and the UK material are by broad geographic area. The 178recordings chosen were cross-referenced with dialect areas as defined by Labov 179et al. (2005) for USA accents and Shackleton (2007) for UK accents, providing 180 both regional coverage and accent variation. As Labov et al. (2005) classify six 181regional accent areas in the USA (North, West, New England, New York City and 182Mid-Atlantic, Midland and South), two recordings representing the West and 183Inland South accent are included from speakers who differ in occupation. We did 184not test New England accents due to lack of quality recordings available for 185 speakers with the desired demographic characteristics. The accents presented to 186both UK and US participants were representative of standard (UK: Received 187Pronunciation and Southeast English accents; USA: “General American" [West 188and Midland] accents) and non-standard variants (Cheshire, 1991; Trudgill \& 189Hannah, 2008) (see Table 1).

190 Comma Gets a Cure is a passage containing terms from J.C. Wells' lexical 191set (1982). The first paragraph included the following words, which highlight 192phonological differences between accents: NURSE, HAPPY, START, NORTH, 193SQUARE, FACE, DRESS, FLEECE, and KIT. The variation in vowel space used for 194these words is listed for RP and General American in this lexical set (Evans $\mathcal{E}$ 195Iverson, 2004), and can be diagnostic for different regional accents (Evans $\mathcal{E}$ 196Iverson, 2004). As such we expect these recordings demonstrate sufficient 
197diversity for participants to either identify or make judgments based on different 198accents.

201Table 2. Attitudinal variables evaluated by participants. Terms in bold are included in the Position202Reputation-Information scale of prestige (Berl, Samarasinghe, Jordan, \& Gavin, 2019). Status,

203solidarity and dynamism dimensions taken from Fuertes et al. (2012).

\begin{tabular}{|c|c|c|c|}
\hline Unclassified & Status & Solidarity & Dynamism \\
\hline $\begin{array}{l}\text { prestigious } \\
\text { powerful } \\
\text { reputable } \\
\text { respected } \\
\text { successful } \\
\text { driven } \\
\text { skilled } \\
\text { warm } \\
\text { comforting } \\
\text { enthusiastic }\end{array}$ & $\begin{array}{l}\text { high social status } \\
\text { wealthy } \\
\text { (un)intelligent } \\
\text { educated } \\
\text { (un)ambitious } \\
\text { talented } \\
\text { clear }\end{array}$ & $\begin{array}{l}\text { (un)kind } \\
\text { good natured }\end{array}$ & $\begin{array}{l}\text { hardworking } \\
\text { friendly } \\
\text { aggressive } \\
\text { active } \\
\text { confident }\end{array}$ \\
\hline
\end{tabular}

204

205We selected attitudinal variables across domains of status, solidarity and 206dynamism based on the most common terms from previous language attitude 207studies (Fuertes et al., 2012). We also designed this experiment to test the 208Position-Reputation-Information (PRI) scale of individual prestige, the results of 209which we have presented and discussed in a separate paper (Berl et al., 2019) 210(see Table 2). We include PRI terms to capture aspects of prestige not previously 211considered in other language attitude studies (Brown et al., 1985; Callan $\&$ 212Gallois, 1987; Fuertes et al., 2012; Giles, 1970; Gill, 1994; Levin, Giles, \& Garrett, 2131994). We asked participants to rate accents for the terms in Table 2 where 1 214 was 'strongly agree' and 7 was 'strongly disagree'. The scale was reversed for 215 some of the terms to ensure that participants' attention was held and to reduce 216response bias (Schriesheim \& Hill, 1981). Negative forms of the intelligent, 217ambitious and kind were used by supplying "un-" as a prefix. We randomised the 218 order in which we asked participants about these terms for each accent 219recording. An additional artificial speech recording was included with 220instructions to rate all terms beginning with consonants a "7" and all terms 221 beginning with vowel a " 1 " as an attention check. 
224We prepared and analysed data using the stringr, reshape, FactoMineR and base 225R packages. Participants vary in how they use the Likert scale, so we calculated z226 scores so that responses were comparable to the mean. Although we included 227the term "prestigious", previous research shows that 'prestige' is multifaceted 228and participants operationalise various definitions of prestige in experimental 229contexts (Berl et al., 2019). A Principal Component Analysis (PCA) was run to 230capture the majority of the data with a reduced number of variables. The PCA 231was conducted in the FactoMineR and factoextra packages, Welch's ANOVA was 232carried out using one way tests with all other statistical tests carried out in the 233 base $R$ package. Boxplots were created using ggplot2.

\section{4}

\section{3. $\underline{\text { Results }}$}

236

237To consolidate the number of variables, we ran a PCA on all respondents' data for 238their evaluative ratings on the different attitude variables (e.g. friendly, skilled) 239across accents. We find that attitudinal variables cluster. Five components have 240eigenvalues greater than 1, which accounts for $56.2 \%$ of the variation.

241Component 1 accounts for $28.5 \%$ of variance and terms here relate to status or 242 prestige domains. Component 2 accounts for $13 \%$ of variance and corresponds 243to friendliness, or terms that we would expect in line with the solidarity and 244dynamism domains (Figure 1). We also compared these dimensions to how 245"prestigious" (Figure 2) and "friendly" (Figure 3) participants rated the different 246accents Components 3, 4 and 5 explains 5.7\%, 5.3\% and 3.8\% of the variance, 247respectively. Component loadings for all attitudinal variables can be found in 248Table S1.

249 Attitudinal measures of "ambitious" (-0.54) and "clear" (-0.39) correlated 250negatively with the prestige dimension, a result which contradicts previous 251research arguing that both terms are status driven (Fuertes et al., 2012). In 252support of this finding, in our other work both of these terms also dropped out of 253the PRI scale of individual prestige due to clustering with other domains ("clear") 254or low salience for prestige with participants ("ambitious”) (Berl et al., 2019). 255These results support the omission of these terms from status or prestige 
256domains. However, the negative relationship between "kind" and the friendliness 257dimension is also unexpected. However, as "kind" was one of the reversed terms 258and presented to participants in the negative form "unkind", this may be due to 259participants losing attention. We found that participants were less inclined to 260rate reversed terms at extreme parts of the scale.

261

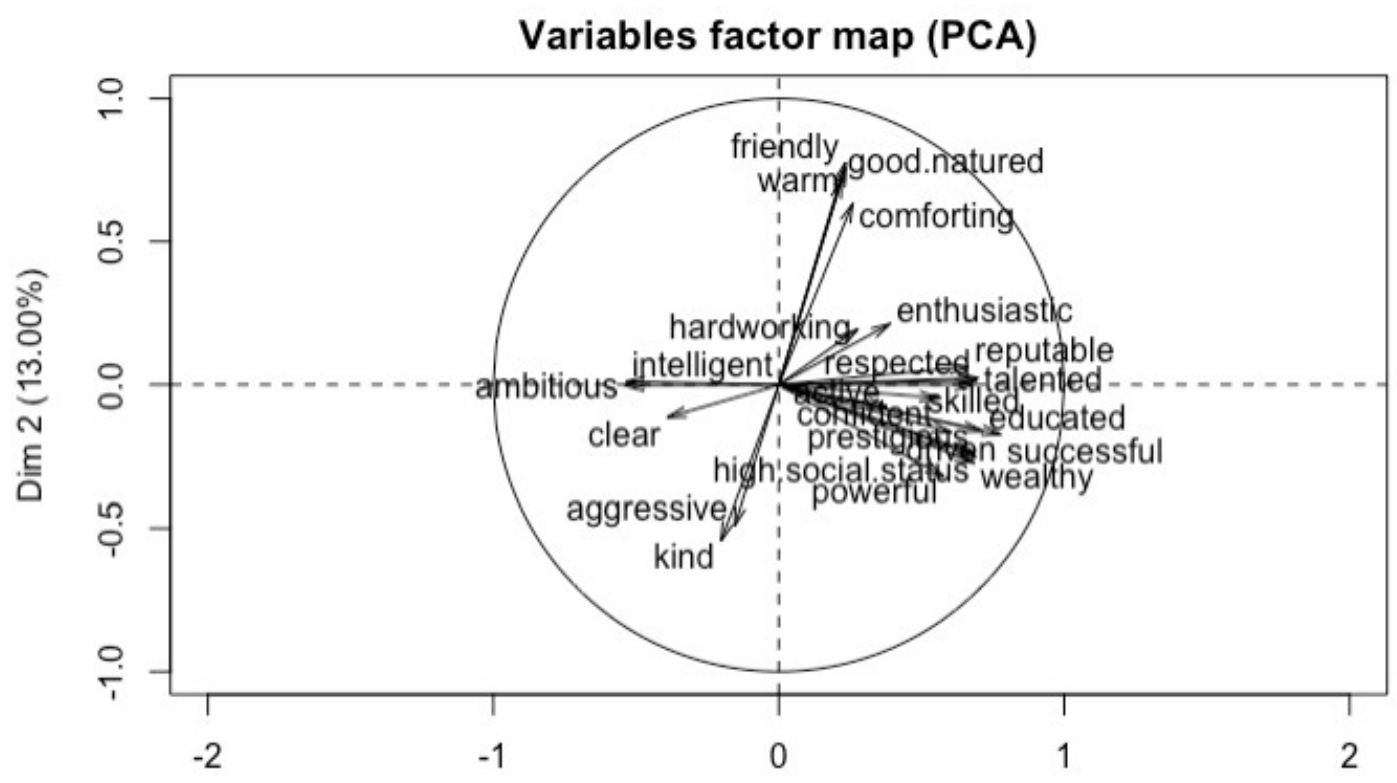

262

$\operatorname{Dim} 1(28.46 \%)$

263Figure 1. Principal Components Analysis (PCA) showing attitudinal variables along Prestige (Dim 1) 264and Friendliness (Dim 2) dimensions.

265

266Assumptions for normality and homogeneity of variance were not met for the 267one-way ANOVAs for both prestige and friendliness; therefore, we deemed 268sample size sufficient for Welch’s ANOVA. For the prestige dimension (Figure 2), 269we found a statistically significant difference between accents $(F(15)=$ 270134.84, $\mathrm{p}<0$.001). Pairwise comparisons using Wilcoxon rank sum tests using 271the Benjamini and Hochberg $(\mathrm{BH})$ p-value adjustment method found significant 272differences between participant's evaluations of prestige for the accents 273highlighted in Table S2. These results demonstrate variance in responses to 274accent prestige and are consistent with the hypothesis that standard accents (e.g. 275Received Pronunciation and General American accents) are rated more 276favourably for prestige over non-standard accents. Participants rated the Welsh 277accent favourably for prestige despite previous studies concluding that Welsh is 
278usually ranked as middling for prestige and social attractiveness (Bishop et al., 2792005; Coupland \& Bishop, 2007; Giles, 1970), but, as this was recorded recently 280 by the authors, this may be due to better sound quality.

281 For the friendliness dimension (Figure 3), Welch's ANOVA $(\mathrm{H}(15)=$ 28244.521, p <0 .001) determined there was a statistically significant difference 283between groups. Pairwise comparisons using Wilcoxon rank sum tests (with the 284BH p-value adjustment method) showed that were significant differences 285between participant's evaluations of friendliness for the accents highlighted in 286Table S3.

287 Here, we find that Southeast England English is rated most highly for 288prestige by UK participants but ranked considerably lower for friendliness. 289Regional accents from the West of England are considered favourably for 290friendliness. USA participants rated Mid-Atlantic and Western accents 291(consistent with "General American" accents) highly for prestige but rated 292Received Pronunciation as the most prestigious accent. The Inland South accent 293was rated low for prestige but highly for friendliness.

294 
A North Carolina
(Inland South, blue collar)' sw England Scotland Yorkshire NW England -

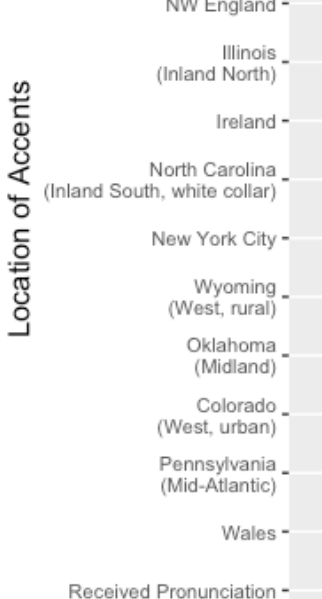
SE England -

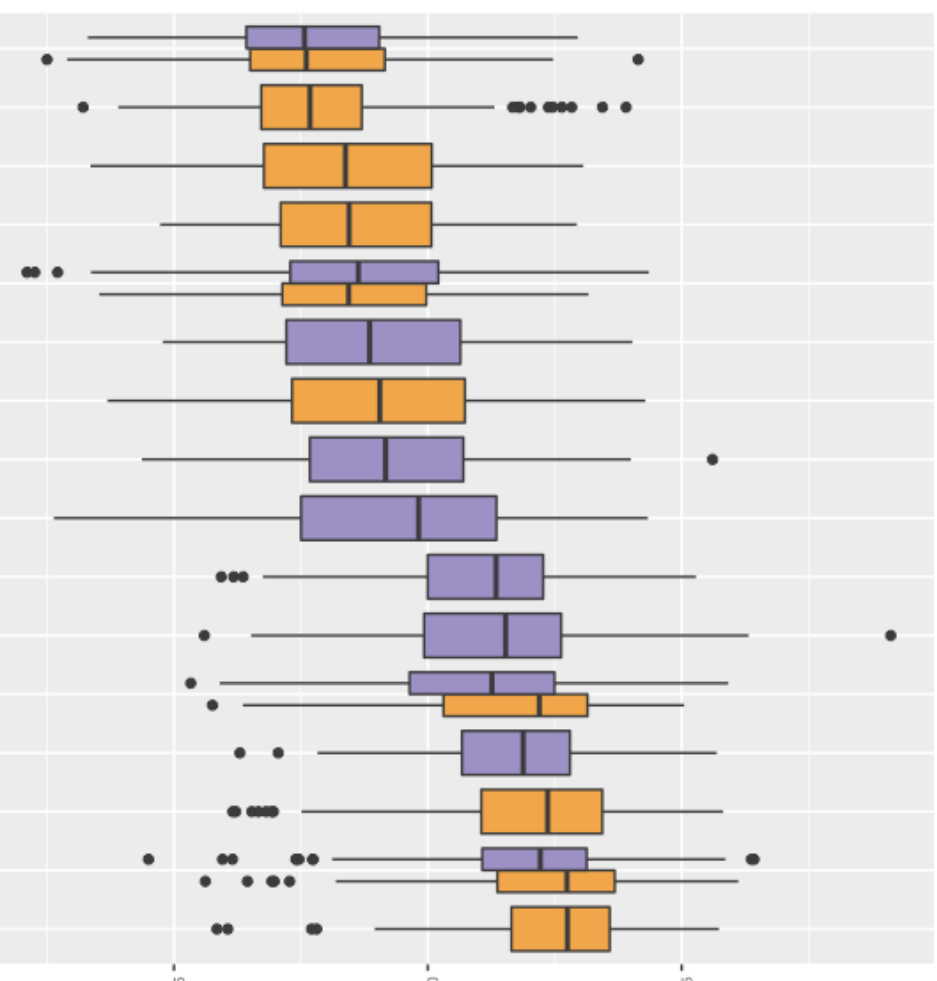

Dim. 1 (Prestige)

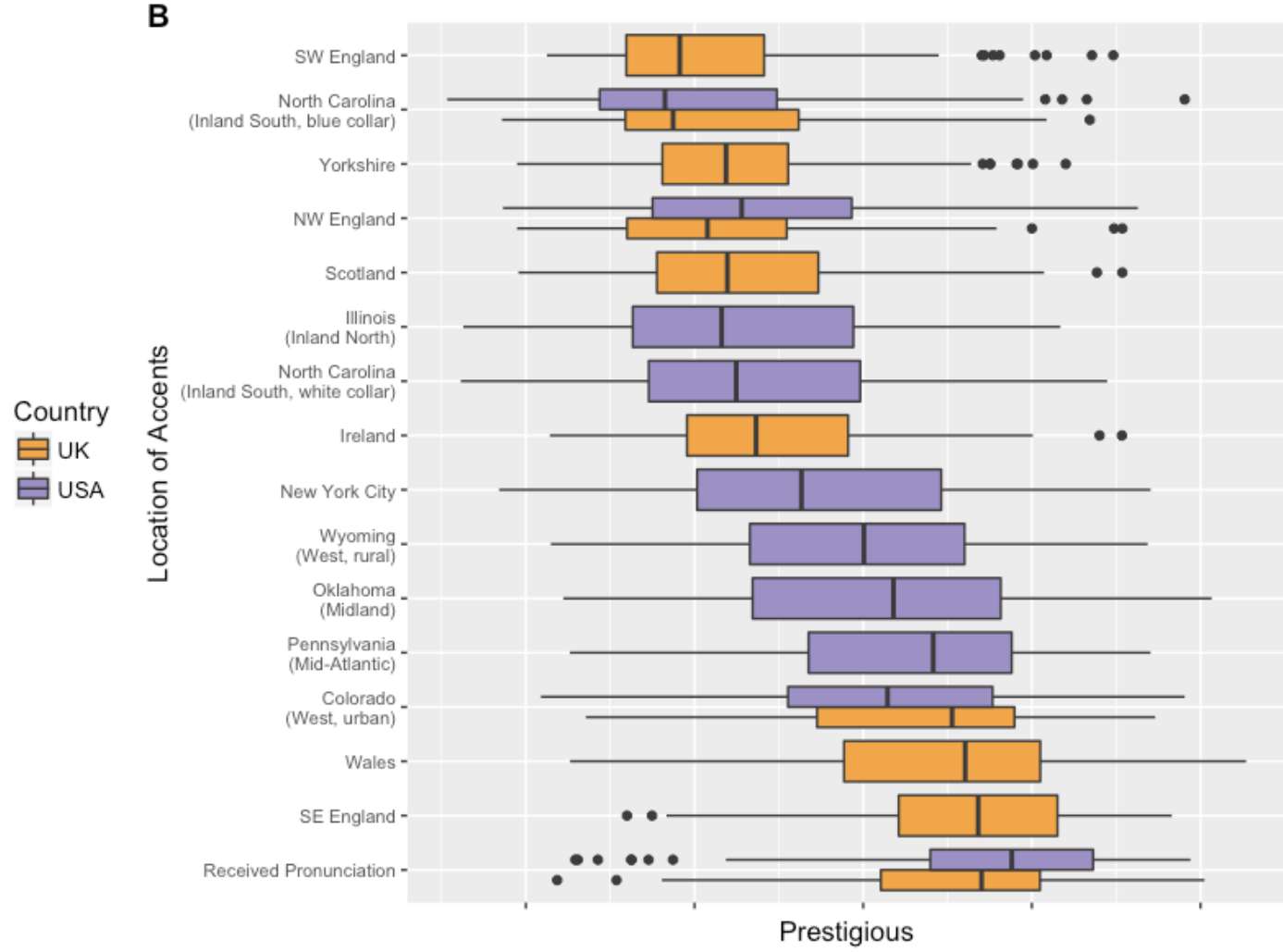

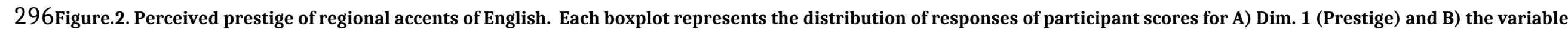

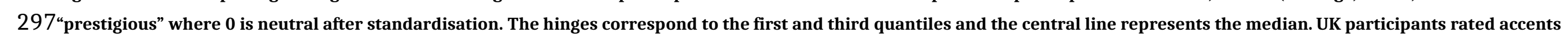
298 with orange boxplots and US participants rated accents with purple boxplots. Accents with two boxplots were presented to participants in both locations. 
A

301
Colorad
(West, urbar

New York City -

(Inland North)

Oklahoma
(Midland)"

SE England -

Scottand -

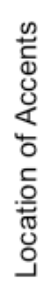

Wales

Pennsylvania
(Mid-Atlantic)

Wyoming
west nurall

Noth Carolina
(Inland South, blue collar)

North Carolina
(Inland South, white collar)"

Yorkshire -

NW England -

SW England -

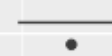

$\bullet$

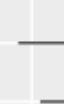
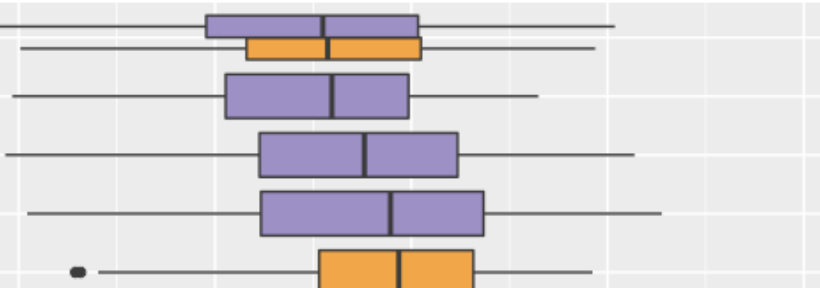

-
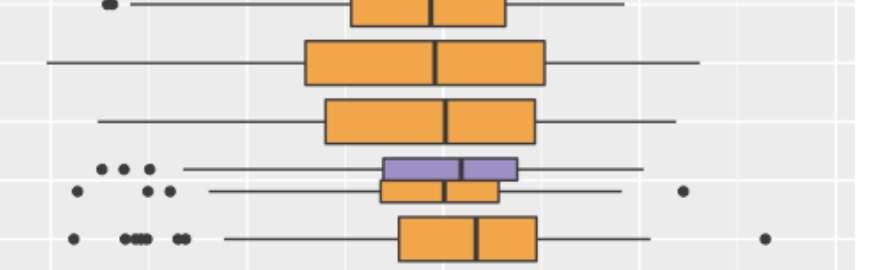

$\infty$

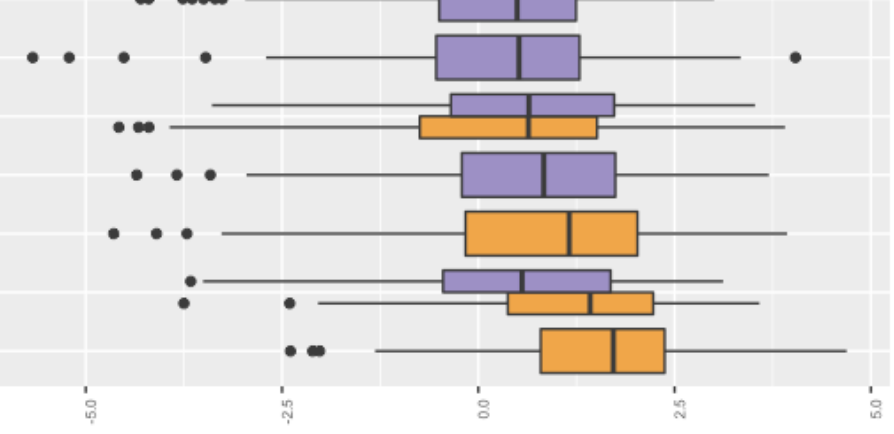

Dim. 2 (Friendliness)

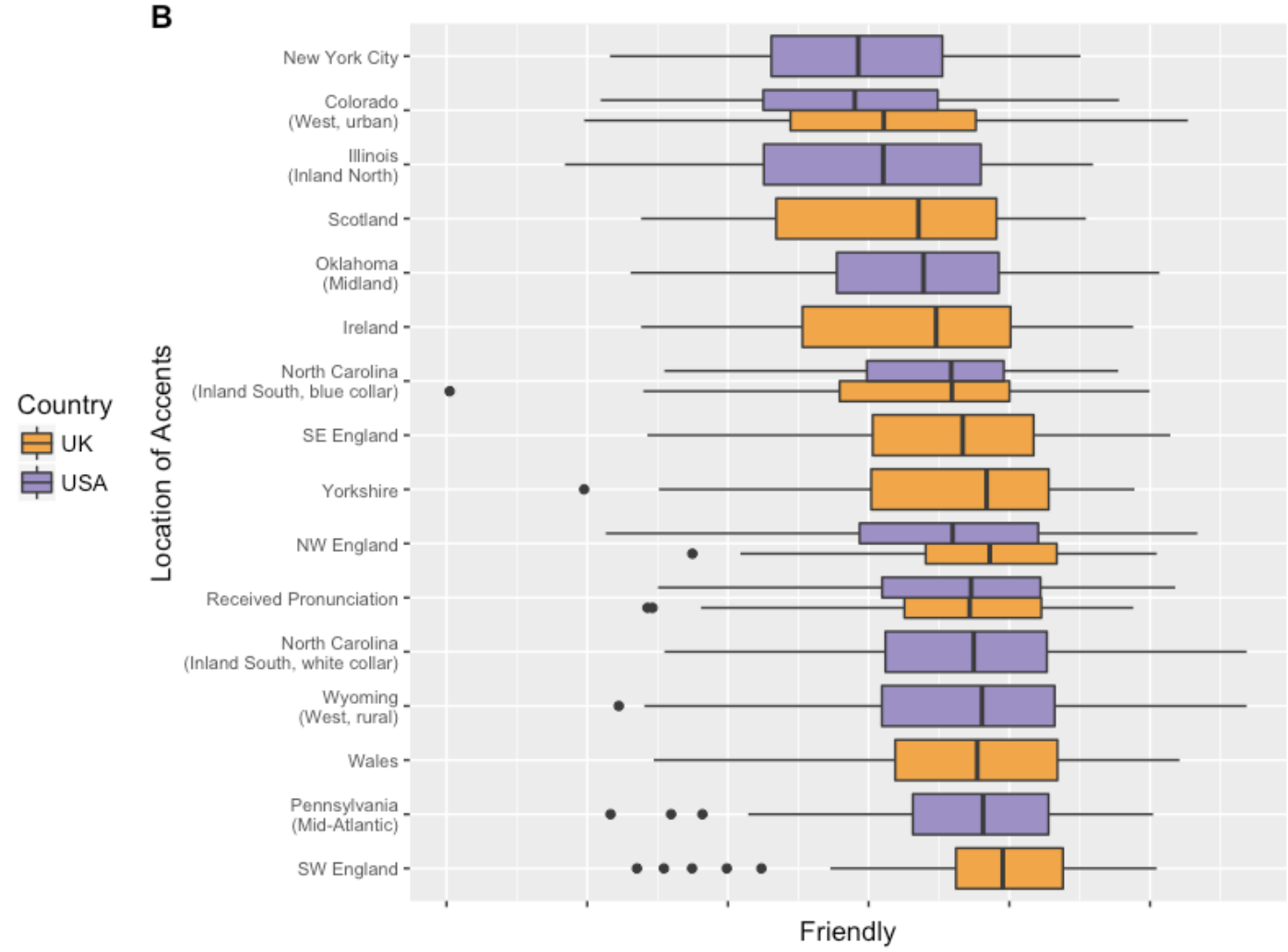

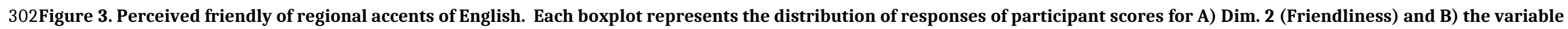

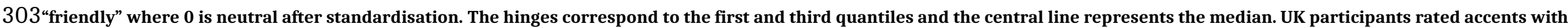
304orange boxplots and US participants rated accents with purple boxplots. Accents with two boxplots were presented to participants in both locations. 
$307 \quad 4.1$ Accents can be used to index social characteristics

3080ur results show that participants are able to make discriminatory judgments 309about the social characteristics of speakers based on accent alone. In the absence 310 of any other information and provided with the same content, participants 311 differentially rated speakers across many attitudinal variables (Figure $S 1$ ). The 312 results of our PCA suggest that attitudinal variables cluster along dimensions 313 that might index prestige and friendliness. That these categories can be 314 manifested through accent is potentially useful because these domains also 315 broadly correspond to prestige and familiarity biases in the CE literature, which 316 suggests that accent might be operationalised as a cue for these factors in CE 317experiments.

318 4.2 Accents demonstrate differential prestige 320For British and American English speakers, accents show differential prestige 321(Figure 2). Participants rated the "General American" cluster of accents 322(West/Midlands) and RP-all standard forms of English-favourably for prestige 323across both locations. This finding contributes to a body of research suggesting 324that we associate prestige with standard varieties (Brown et al., 1985; Coupland, 3252003; Coupland \& Bishop, 2007; Giles, 1971, 1973; Giles \& Sassoon, 1983; 326Milroy, 2007; Milroy \& Milroy, 1999). However, participants in both countries 327rated RP highest for prestige, implying that the prestige of this particular variety 328is stable and widespread. This result has been found elsewhere, which is likely to 329be an artefact of the British colonial past (Stewart, Bouchard Ryan, \& Giles, 3301985). "General American" accents were also rated highly so our results are 331 unlikely to be a case of cultural cringe, whereby participants are less favourable 332towards accents similar to their own (Bayard et al., 2001; Eisenchlas $\mathcal{E}$ 333Tsurutani, 2011; Pickles, 2011). We might expect that some level of in-group 334association in necessary for prestige to be relevant, however, here we show that 335 prestige can be afforded to out-group members. As US participants rated RP as 336having the highest prestige, this suggests that we cannot make assumptions 
337 about the relevancy of accents and should be testing and locally calibrating the 338accents used in accent-based studies.

341In line with previous studies (Coupland \& Bishop, 2007; Giles, 1970; Kinzler \& 342DeJesus, 2013), the top five friendliest accents (SW England, NW England, 343Yorkshire, blue collar North Carolina, white collar North Carolina) rated by our 344 participants are regional/non-standard accents (see Figure 3). However, 345 standard accents varied in their perceived friendliness. Prior research provides 346 evidence to suggest that we associate stereotypes with location-specific accents 347(Boucher et al., 2013; Gluszek \& Dovidio, 2010; Ladegaard \& Sachdev, 2006), and 348 so it may be more difficult to reconcile both positive and negative stereotypes 349 with generalised accents. However, standard accents may still be deployed as an 350outgroup when considering solidarity-related biases because they are usually 351 non-geographically specific. In this case it is difficult to form a shared identity 352 based on accent alone.

$354 \quad 4.4$ Prestigious accents are less likely to be considered friendly 355In general, participants perceived location-specific non-standard accents as 356having lower prestige. Conversely, of the four accents presented to both listeners 357in both locations, participants perceived those deemed as having lower prestige 358as being friendlier, which may suggest that a trade-off exists between being 359deemed prestigious or friendly (Coupland \& Bishop, 2007; Kinzler \& DeJesus, 3602013; Laiwani et al., 2005; Morales et al., 2012; Stewart et al., 1985).

361 However, if we are to posit that non-standard regional accents are 362 perceived as friendlier, RP might be considered a special case. Participants did 363 not rate $\mathrm{RP}$ as unfriendly, despite its high prestige score, as expected for both UK 364and US participants. This outcome may be because RP has often been associated 365with the 'Queen's English,' which has variable connotations depending on the 366listener. For example, other language attitude surveys found older individuals 367and participants in Southeast England hold positive attitudes towards ‘Queen's 368English', but this accent is deemed socially unattractive in Celtic fringe regions 
369such as Northern Ireland, Scotland and Wales, potentially a consequence of 370socio-political context (Bishop et al., 2005; Coupland \& Bishop, 2007). As such, $371 R P$ may index a specific socio-political context that may be deemed socially 372attractive internationally.

373

\section{$374 \quad 4.5$ Accents as a robust proxy for prestige}

375Across both populations, participants' responses to the relevant standard and 376regional/non-standard accents were similar. Participants were also able to 377identify the accents from the alternative country as high or low prestige, and 378 evaluated these accents in line with participants from the other country. This is 379an interesting finding because, although we might expect associations with 380accent to be based on familiarity, our results suggest that these two populations 381 share attitudes toward accent notwithstanding group affiliation or lack thereof. 382This may be partially due to working with Global North populations only, who 383may have greater exposure to multiple accents of English in media. Nevertheless, 384 for the populations studied, our results replicate previous language attitude 385surveys (Bishop et al., 2005; Boucher et al., 2013; Bresnahan, Ohashi, Nebashi, 386Liu, \& Shearman, 2002; Giles, 1970; Kinzler \& DeJesus, 2013; Ladegaard \& 387Sachdev, 2006), suggesting that these attitudes are stable and widespread, and 388therefore can be effectively deployed as a cue for prestige, and potentially other 389 social information.

390Accent has not previously been used in social transmission experiments, and 391prestige has often been established through attentional cues or deference 392(Atkisson, Mesoudi and O’Brien, 2012; Chudek et al., 2012; Henrich and Gil393White, 2001; Jiménez and Mesoudi, 2019b). However, in any transmission event 394 that relies upon the use of speech or verbal cues, accent prestige may be an 395additional confound that is unaccounted for. We suggest that researchers at the 396very least should consider the effects on their studies if accent is a carrier of 397 social information cues.

398 Accent offers further potential benefits to the experimental study of 399 prestige. Individuals can independently evaluate whether a person is prestigious 400based on their own information, without relying on cues from third parties. 
401Relatedly, attention/deference measures can only convey prestige to the 402individual receiving the attention, whereas accent prestige is a property of 403(multiple) individuals and groups, and allows for greater scope in exploring 404 models of social information transmission. The variance in prestige across 405accents of English shows that accent can be used as an indicator of prestige in the 406absence of other prestige information, and, thus, could be used as a broadly407shared cue of prestige bias. Aspects of language (e.g. accent, prosody, gesture etc) 408beyond propositional content have been underexplored by social learning and 409cultural evolution researchers and we hope our results show that there is much 410to learn. Finally, further research to examine prestige evaluation effects in 411languages other than English would be valuable in establishing this phenomena 412 more generally.

\section{5. Acknowledgments}

415The recordings used in this project (with the exception of Colorado and Wales, 416 which were recorded by the authors) are used by special permission of the 417International Dialects of English Archive, online at 418http://www.dialectsarchive.com. Comma Gets a Cure is copyright 2000 Douglas 419N. Honorof, Jill McCullough \& Barbara Somerville, text available online at: http:// 420www.dialectsarchive.com/comma-gets-a-cure. The Max Planck Institute for the 421Science of Human History funded the project. 


\section{References}

424

425Alford, R. L., \& Strother, J. B. (1990). Attitudes of Native and Nonnative Speakers

426 Toward Selected Regional Accents of U.S. English. TESOL Quarterly, 24(3), 427 479-496. https://doi.org/10.2307/3587231

428Atkisson, C., Mesoudi, A., \& O’Brien, M. J. (2012). Adult learners in a novel

429 environment use prestige-biased social learning. Evolutionary Psychology:

430 An International Journal of Evolutionary Approaches to Psychology and

431 Behavior., 10(3), 519-537.

432Bayard, D., Weatherall, A., Gallois, C., \& Pittam, J. (2001). Pax Americana? Accent

433 attitudinal evaluations in New Zealand, Australia and America. Journal of

434 Sociolinguistics, 5(1), 22-49. https://doi.org/10.1111/1467-9481.00136

435Berl, R. E. W., Samarasinghe, A. N., Jordan, F. M., \& Gavin, M. C. (2019). The

436 Position-Reputation-Information (PRI) scale of individual prestige.

437 SocArXiv [Preprint]. https://doi.org/10.31235/osf.io/426n8

438Bishop, H., Coupland, N., \& Garrett, P. (2005). Conceptual accent evaluation:

439 Thirty years of accent prejudice in the UK. Acta Linguistica Hafniensia, $440 \quad 37(1), 131-154$. https://doi.org/10.1080/03740463.2005.10416087

441Boucher, C. J., Hammock, G. S., McLaughlin, S. D., \& Henry, K. N. (2013).

442 Perceptions of Competency as a Function of Accent. Psi Chi Journal of 443 Psychological Research, 18(1), 27-32.

444Brand, C. O., \& Mesoudi, A. (2019). Prestige and dominance-based hierarchies 445 exist in naturally occurring human groups, but are unrelated to task$446 \quad$ specific knowledge. Royal Society Open Science, 181621. 
447Bresnahan, M. J., Ohashi, R., Nebashi, R., Liu, W. Y., \& Shearman, S. M. (2002).

448 Attitudinal and affective response toward accented English. Language $\mathcal{E}$

$449 \quad$ Communication, 22(2), 171-185.

450Brown, B. L., Giles, H., \& Thakerar, J. N. (1985). Speaker evaluations as a function

$451 \quad$ of speech rate, accent and context. Language \& Communication, 5(3), 207-

$452 \quad 220$.

453Callan, V. J., \& Gallois, C. (1987). Anglo-Australians' and immigrants' attitudes

454 toward language and accent: A review of experimental and survey

455 research. International Migration Review, 48-69.

456Cheshire, J. (1991). English around the World: Sociolinguistic Perspectives.

457 Cambridge University Press.

458Chudek, M., Heller, S., Birch, S., \& Henrich, J. (2012). Prestige-biased cultural

459 learning: bystander's differential attention to potential models influences

460 children's learning. Evolution and Human Behavior, 33(1), 46-56. https://

461 doi.org/10.1016/j.evolhumbehav.2011.05.005

462Clopper, C. G., \& Pisoni, D. B. (2006). The Nationwide Speech Project: A new

463 corpus of American English dialects. Speech Communication, 48(6), 633-

464 644. https://doi.org/10.1016/j.specom.2005.09.010

465Cohen, E. (2012). The Evolution of Tag-Based Cooperation in Humans: The Case

466 for Accent. Current Anthropology, 53(5), 588-616.

467 https://doi.org/10.1086/667654

468Coupland, N. (2003). Sociolinguistic authenticities. Journal of Sociolinguistics, 469 7(3), 417-431. https://doi.org/10.1111/1467-9481.00233

470Coupland, N., \& Bishop, H. (2007). Ideologised values for British accents. Journal 471 of Sociolinguistics, 11(1), 74-93. 
472Daloz, J. (2009). The Sociology of Elite Distinction: From Theoretical to

473 Comparative Perspectives. Springer.

474Eisenchlas, S. A., \& Tsurutani, C. (2011). You sound attractive! Perceptions of 475 accented English in a multi-lingual environment. Australian Review of $476 \quad$ Applied Linguistics, 34(2), 216.

477Evans, B. G., \& Iverson, P. (2004). Vowel normalization for accent: An

478 investigation of best exemplar locations in northern and southern British

479 English sentences. The Journal of the Acoustical Society of America, 115(1),

$480 \quad 352-361$. https://doi.org/10.1121/1.1635413

481Fişek, M. H., Berger, J., \& Norman, R. Z. (2005). Status cues and the formation of 482 expectations. Social Science Research, 34(1), 80-102.

483 https://doi.org/10.1016/j.ssresearch.2003.10.004

484Fuertes, J. N., Gottdiener, W. H., Martin, H., Gilbert, T. C., \& Giles, H. (2012). A

485 meta-analysis of the effects of speakers' accents on interpersonal

486 evaluations: Effects of speakers' accents. European Journal of Social

487 Psychology, 42(1), 120-133. https://doi.org/10.1002/ejsp.862

488Giles, H. (1970). Evaluative Reactions to Accents. Educational Review, 22(3), 211489 227. https://doi.org/10.1080/0013191700220301

490Giles, H. (1971). Patterns of evaluation to RP, South Welsh and Somerset 491 accented speech. British Journal of Social and Clinical Psychology, 10(3), $492 \quad 280-281$.

493Giles, H. (1973). Communicative effectiveness as a function of accented speech. $494 \quad$ Speech Monographs, 330-331.

495Giles, H., \& Sassoon, C. (1983). The effect of speaker's accent, social class 496 background and message style on British listeners' social judgements. 
Language \& Communication, 3(3), 305-313.

498 https://doi.org/10.1016/0271-5309(83)90006-X

499Gill, M. M. (1994). Accent and stereotypes: Their effect on perceptions of teachers

500 and lecture comprehension. Retrieved from http://www.tandfonline.com/

$501 \quad$ doi/abs/10.1080/00909889409365409

502Gluszek, A., \& Dovidio, J. F. (2010). The Way They Speak: A Social Psychological

503 Perspective on the Stigma of Nonnative Accents in Communication.

504 Personality and Social Psychology Review, 14(2), 214-237.

$505 \quad$ https://doi.org/10.1177/1088868309359288

506Harris, P. L., \& Corriveau, K. H. (2011). Young children's selective trust in 507 informants. Philosophical Transactions of the Royal Society B: Biological $508 \quad$ Sciences, 366(1567), 1179-1187.

509 https://doi.org/10.1098/rstb.2010.0321

510Hawkey, J. (2016). Developing Discussion of Language Change Into a Three-

511 Dimensional Model of Linguistic Phenomena: Three-Dimensional Model

512 of Linguistic Phenomena. Language and Linguistics Compass, 10(4), 176-

513 190. https://doi.org/10.1111/lnc3.12180

514Henrich, J., \& Gil-White, F. J. (2001). The evolution of prestige: Freely conferred

515 deference as a mechanism for enhancing the benefits of cultural

516 transmission. Evolution and Human Behavior, 22(3), 165-196.

517Honorof, D. N., McCullough, J., \& Somerville, B. (2000). Comma gets a cure: A

518 diagnostic passage for accent study (p. 1) [Technical Report].

519Jiménez, Á. V., \& Mesoudi, A. (2019a). Prestige does not affect the social

520 transmission of controversial arguments. PsyArXiv [Preprint].

521 https://doi.org/10.31234/osf.io/3u9wh 
522Jiménez, Á. V., \& Mesoudi, A. (2019b). Prestige-biased social learning: current

523 evidence and outstanding questions. Palgrave Communications, 5(1).

524 https://doi.org/10.1057/s41599-019-0228-7

525Kinzler, K. D., Dupoux, E., \& Spelke, E. S. (2007). The native language of social

526 cognition. Proceedings of the National Academy of Sciences, 104(30),

527 12577-12580. https://doi.org/10.1073/pnas.0705345104

528Kinzler, K. D., Corriveau, K. H., \& Harris, P. L. (2011). Children's selective trust in

529 native-accented speakers: Selective trust in native-accented speakers.

530 Developmental Science, 14(1), 106-111. https://doi.org/10.1111/j.1467-

$531 \quad 7687.2010 .00965 . x$

532Kinzler, K. D., \& DeJesus, J. M. (2013). Northern = smart and Southern = nice: The

533 development of accent attitudes in the United States. The Quarterly

$534 \quad$ Journal of Experimental Psychology, 66(6), 1146-1158.

$535 \quad$ https://doi.org/10.1080/17470218.2012.731695

536Kinzler, K. D., Shutts, K., DeJesus, J., \& Spelke, E. S. (2009). Accent trumps race in

537 guiding children's social preferences. Social Cognition, 27(4), 623-634.

$538 \quad$ https://doi.org/10.1521/soco.2009.27.4.623

539Labov, W., Ash, S., \& Boberg, C. (2005). The atlas of North American English:

$540 \quad$ Phonetics, phonology and sound change.

541Ladegaard, H. J., \& Sachdev, I. (2006). 'I Like the Americans... But I Certainly

542 Don't Aim for an American Accent': Language Attitudes, Vitality and

$543 \quad$ Foreign Language Learning in Denmark. Journal of Multilingual \&

544 Multicultural Development, 27(2), 91-108. 
545Laiwani, A. K., Lwin, M., \& Li, K. L. (2005). Consumer Responses to English Accent

546 Variations in Advertising. Journal of Global Marketing, 18(3/4), 143-165.

547 https://doi.org/10.1300/J042v18n03・07

548Lev-Ari, S., \& Keysar, B. (2010). Why don't we believe non-native speakers? The

549 influence of accent on credibility. Journal of Experimental Social

$550 \quad$ Psychology, 46(6), 1093-1096.

551 https://doi.org/10.1016/j.jesp.2010.05.025

552Levin, H., Giles, H., \& Garrett, P. (1994). The effects of lexical formality and accent 553 on trait attributions. Language \& Communication, 14(3), 265-274.

554Lwin, M., \& Wee, C.-H. (1999). The Effect of an Audio Stimulus: Accents in English 555 Language on Cross-Cultural Consumer Response to Advertising. Journal 556 of International Consumer Marketing, 11(2), 5.

557Meyerhoff, M. (2011). Introducing Sociolinguistics (Second). Oxford: Routledge. 558Milroy, J. (Ed.). (2007). The Ideology of the Standard Language. In The Routledge 559 companion to sociolinguistics (pp. 133-139). London; New York:

$560 \quad$ Routledge.

561Milroy, J., \& Milroy, L. (1999). Authority in Language: Investigating Standard $562 \quad$ English. Psychology Press.

563Morales, A. C., Scott, M. L., \& Yorkston, E. A. (2012). The Role of Accent 564 Standardness in Message Preference and Recall. Journal of Advertising, 565 41(1), 33-46. https://doi.org/10.2753/JOA0091-3367410103

566Pickles, K. (2011). Transnational History and Cultural Cringe: Some Issues for 567 Consideration in New Zealand, Australia and Canada: Transnational 568 History and Cultural Cringe. History Compass, 9(9), 657-673.

569 https://doi.org/10.1111/j.1478-0542.2011.00794.x 
570Rubin, D. L., \& Smith, K. A. (1990). Effects of accent, ethnicity, and lecture topic on

571 undergraduates' perceptions of nonnative English-speaking teaching

572 assistants. International Journal of Intercultural Relations, 14(3), 337-353.

573Schriesheim, C. A., \& Hill, K. D. (1981). Controlling Acquiescence Response Bias

574 by Item Reversals: The Effect on Questionnaire Validity. Educational and

$575 \quad$ Psychological Measurement, 41(4), 1101-1114.

$576 \quad$ https://doi.org/10.1177/001316448104100420

577Shackleton, R. G. (2007). Phonetic variation in the traditional English dialects: A 578 computational analysis. Journal of English Linguistics, 35(1), 30-102.

579Stewart, M. A., Bouchard Ryan, E., \& Giles, H. (1985). Accent and social class

580 effects on status and solidarity evaluations. Personality and Social

$581 \quad$ Psychology Bulletin, 11(1), 98-105.

582Trudgill, P., \& Hannah, J. (2008). International English: a guide to varieties of 583 standard English (5th ed). London: Hodder Education.

584Tsalikis, J., Ortiz-Buonafina, M., \& LaTour, M. S. (1992). The Role of Accent on the 585 Credibility and Effectiveness of the International Business Person: The 586 Case of Guatemala. International Marketing Review, 9(4). https://doi.org/ $587 \quad 10.1108 / 02651339210017136$

588Wang, H., \& Heuven, V. J. van. (2004). Cross-linguistic confusion of vowels 589 produced and perceived by Chinese, Dutch and American speakers of 590 English. Linguistics in the Netherlands, 21, 205-216.

591Wang, Z., Arndt, A. D., Singh, S. N., Biernat, M., \& Liu, F. (2013). “You Lost Me at 592 Hello": How and when accent-based biases are expressed and suppressed. 593 International Journal of Research in Marketing, 30(2), 185-196.

594 https://doi.org/10.1016/j.ijresmar.2012.09.004 
595Wells, J. C. (1982). Accents of English: The British Isles (Vol. 2). Cambridge:

596 Cambridge University Press.

597 